\title{
Sick building syndrome among parents of preschool children in relation to home environment in Chongqing, China
}

\author{
WANG Juan ${ }^{1,2}$, LI BaiZhan ${ }^{1 *}$, YANG Qin ${ }^{1}$, WANG Han ${ }^{1}$, NORBACK Dan ${ }^{2} \&$ SUNDELL Jan ${ }^{1,3}$ \\ ${ }^{1}$ Key Laboratory of Three Gorges Reservoir Region's Eco-Environment, Ministry of Education, Chongqing University, Chongqing 400045, China; \\ ${ }^{2}$ Department of Medical Sciences, Uppsala University, Uppsala SE-75185, Sweden; \\ ${ }^{3}$ Institute of Built Environment, Department of Building Science, Tsinghua University, Beijing 100084, China
}

Received January 9, 2013; accepted March 7, 2013; published online April 22, 2013

\begin{abstract}
The prevalence and risk factors of sick building syndrome (SBS) symptoms in domestic environments were studied by a questionnaire survey on the home environment. Parents of 5299 3-6 years old children from randomly selected kindergartens in Chongqing, China returned completed questionnaires between December 2010 and April 2011. The prevalence of parents' SBS symptoms (often (every week) compared with never) were: $11.4 \%$ for general symptoms, $7.1 \%$ for mucosal symptoms and $4.4 \%$ for skin symptoms. Multiple logistic regressions were applied controlling for gender and asthma/allergic rhinitis/eczema. Living near a main road or highway was a strong risk factor for general symptoms (adjusted odds ratio, aOR=2.16, $P<0.001$ ), skin symptoms $(\mathrm{aOR}=2.69, P<0.001)$, and mucosal symptoms $(\mathrm{aOR}=1.63, P<0.01)$. Redecoration was a risk factor for general symptoms $(\mathrm{aOR}=2.00, P<0.001)$, skin symptoms $(\mathrm{aOR}=1.66, P<0.01)$, and mucosal symptoms $(\mathrm{aOR}=1.66, P<0.05)$. New furniture was a risk factor for general symptoms $(\mathrm{aOR}=2.16, P<0.001)$ and skin symptoms $(\mathrm{aOR}=1.67, P<0.01)$. Dampness related problems (mould spot, damp stain, water damage and condensation) were all risk factors for SBS symptoms, as was the presence of cockroaches, rats, and mosquitoes/flies and use of incense. Protective factors include cleaning the child's bedroom every day and frequently exposing bedding to sunshine. In conclusion, adults' SBS symptoms were related to factors of the home environment.
\end{abstract}

home, sick building syndrome, dampness, indoor environment

Citation: Wang J, Li B Z, Yang Q, et al. Sick building syndrome among parents of preschool children in relation to home environment in Chongqing, China. Chin Sci Bull, 2013, 58: 4267-4276, doi: 10.1007/s11434-013-5814-2

Since the mid-1970s, symptoms and complaints have been increasingly reported by occupants of certain buildings or specific rooms. In 1983, WHO referred to a suite of symptoms as sick building syndrome (SBS) [1]. Typically, SBS symptoms disappear after the occupant leaves the building or room. SBS symptoms can be grouped into general symptoms (headache, fatigue, feeling heavy-headed and difficulty concentrating), mucosal symptoms (eye, throat and nose irritations or coughing) and skin symptoms (for example on the face, hands or scalp). A study from 1986 found that up to $30 \%$ of new and rebuilt buildings had higher rates of complaints than what was regarded as normal, and that the sensation of dry mucous membranes is most frequently re-

*Corresponding author (email: baizhanli@cqu.edu.cn) ported in the building illness syndrome [2].

Since WHO's first reports on SBS, a large number of SBS studies have been conducted [3]. These studies characterized potential risk factors for SBS symptoms. Certain building and room factors, airborne pollutants, gender, atopy and working conditions were important risk factors. In a large study on office workers, a low outdoor-to-indoor air flow rate, ventilation operating hours less than $10 \mathrm{~h}$ per day, and the presence of certain pollution sources, such as copying machines, were associated with an elevated prevalence of SBS symptoms [4]. Later Wargocki et al. [5,6] showed in climate chamber studies that ventilation rates well above the minimum levels prescribed in existing standards and guidelines could reduce SBS symptoms.

SBS is related to both personal and environmental risk 
factors. Numerous studies have shown that female gender [7-11], allergies [3,12] and building dampness [13,14] are SBS risk factors. A low ventilation rate [4-6,15], indoor air pollution [16,17], psychosocial factors [18-20], a sensation of dryness [21], are also SBS risk factors.

However, the mechanisms are still largely unknown. Sensory reactions from the olfactory (odor) and trigeminal (irritation) systems seem to be involved [22-24], and so do cutaneous senses. Presumably there is an interaction involving environmental factors and sensory systems [23]. Immune reactions have a possible role. One study from Taiwan, China showed that oxidative stress associated with volatile organic compounds was also associated with SBSrelated symptoms among office workers [25]. Biomarkers of allergy and inflammation were associated with a higher incidence of SBS symptoms [26].

Most published studies on sick building syndrome (SBS) have dealt with symptoms among office workers. There are few published studies on SBS in relation to domestic exposures. However, a Japanese study of sick house syndrome (SHS), which is defined similarly to SBS, has shown that the presence of dampness (mould) as well as some semivolatile organic compounds (SVOC) was related to an increased risk of SHS [27]. A study from Stockholm reported that people who owned their home reported less "SBS" than those who rented their dwellings [28]. Another cohort study from Sweden showed that dampness in a dwelling was a risk factor for new onset of SBS symptoms [29]. Reducing dampness in buildings has been shown to be important for reducing SBS symptoms in the general population [29].

There are no published studies about SBS in relation to domestic exposures (except some school SBS studies) in China. The main aim of the present study is to estimate the prevalence of SBS symptoms in Chongqing adults with young children, and to characterize domestic environmental factors associated with Chongqing parents' SBS symptoms.

\section{Methods}

\subsection{The survey}

The present study is part of an epidemiological study on children's health and their relation to the home environment in China (China, Children, Homes, Health, CCHH). The study is a parallel to studies conducted in Sweden, Bulgaria, Denmark and USA [30-33], starting with a cross-sectional questionnaire survey and followed by a nested casecontrol study. The survey was carried out from December 2010 to April 2011. The study was approved by an ethical committee.

\subsection{Selection of the study subjects}

The questionnaires were handed out to children's parents through teachers in kindergartens. Three districts (Shaping- ba, Jiulongpo, Yubei) were randomly selected from 9 districts of Chongqing City. Out of the 54 randomly selected kindergartens (15 from Shapingba, 21 from Jiulongpo and 18 from Yubei), 7117 subjects (parents of children aged 1-8 years old) were selected and invited for questionnaire survey. Completed questionnaires were collected one week later by teachers.

\subsection{Questionnaire}

A modified version of the self-administered questionnaire previously used in Sweden Bulgaria and USA [30,31,33] has been used in this study. The questionnaire was slightly modified to be more appropriate for Chinese culture, lifestyle, building structure and interior characteristics.

Questions about SBS symptoms were obtained from the Northern Swedish Office Illness study [4]. They are: During the last 3 months, have you had any (or more) of the following symptoms: (1) Fatigue; (2) Feeling heavy headed; (3) Headache; (4) Nausea/dizziness; (5) Difficulties concentrating; (6) Itching, burning or irritation of the eyes; (7) Irritating, stuffy or runny nose; (8) Hoarse, dry throat; (9) Cough; (10) Dry or flushed facial skin; (11) Scaling/itching scalp or ears; (12) Hands dry, itching, red skin. There are 3 options to choose for each answer: (1) Often (every week); (2) Sometimes; (3) Never.

Questions about demographic information, exposure indicators and building characteristics used for the present analysis were:

(1) Gender;

(2) A history of asthma, allergic rhinitis or eczema (yes/ no);

(3) Current smoking (yes/no);

(4) House site (urban/suburban/rural);

(5) * Whether current residence is near a main road or highway within a distance of $200 \mathrm{~m}$ (yes/no);

(6) Building construction time (before 1980/1980-1990/ 1991-2000/2001-2005/after 2005);

(7) Residence area $\left(\leqslant 40 \mathrm{~m}^{2} / 41-60 \mathrm{~m}^{2} / 61-75 \mathrm{~m}^{2} / 76-100 \mathrm{~m}^{2} /\right.$ $\left.101-150 \mathrm{~m}^{2} />150 \mathrm{~m}^{2}\right)$;

(8) Wall materials on children's bedroom (wall paper/ cement/lime/paint/emulsion paint/other);

(9) Floor materials on children's bedroom (wood/cement/ ceramic tile or stone/laminated floor/other);

(10) * Whether any redecoration has been done since one year before pregnancy (yes/no);

(11) * Whether any new furniture has been bought since 1 year before pregnancy (yes/no);

(12) * Whether subject has reported any mould spot in child's bedroom (yes/no);

(13) * Whether subject has reported any damp stain in child's bedroom (yes/no);

(14) * Whether subject has reported any water damage of current residence (yes/no);

(15) * Whether subject has reported condensation on 
window panels during winter in child bedroom (yes/no);

(16) * Whether subject has seen cockroaches in home before (yes/no);

(17) * Whether subject has seen rats in home before (yes/no);

(18) * Whether subject has seen mosquitoes/flies in home before (yes/no);

(19) Whether subject has used mosquito-repellent incense in home before (yes/no);

(20)* Whether subject has used incense in home before (yes/no);

(21) * Whether subject has pets in home currently (yes/ no); if yes, please indicate it is (cat/dog/rodent (rabbit/rat)/ bird/aquarium fishes or reptiles/other);

(22) * The frequency of cleaning child's bedroom (every day/less than or equal to twice a week);

(23) * The frequency of putting child's bedding to sunshine (frequently/never or rarely);

(24) The frequency of opening window in child's bedroom in winter (frequently/never or rarely).

The meanings of those questions above with “*” will be explained in Section 1.4.

\subsection{Indoor environment risk factors score}

From the 24 questions about demographics, exposure indicators and building characteristics above, an indoor environment risk factor score (0-14) was constructed by using 14 questions which marked with “*”. Question 22 was changed to ask whether the child's bedroom was cleaned everyday (Yes/No, "Yes" was code as " 0 " and "No" was coded as " 1 ") and question 23 was changed to ask whether bedding was put in sunshine frequently (Yes/No, "Yes" was code as " 0 " and "No" was coded as "1"). Each "Yes" responses to any one of the other 12 exposure indicators of home environment which marked with "*" was coded as "1" and each "No" response was coded as " 0 ". The total score was obtained by adding all the scores from 14 questions for each subject.

A category score for sums of numbers of indoor environment risk factors was developed: $0,1,2$ and 3 risk factors out of 14 were scored as $0 ; 4$ risk factors out of 14 were scored as $1 ; 5$ out of 14 were scored as $2 ; 6$ out of 14 were scored as 3 and 7 or more out of 14 were scored as 4 .

\subsection{Statistical analysis}

The analyses were based on cases and controls defined in this study. All analyses of associations between risk factors and SBS symptoms were made for a case group of subjects compared with a control group. Case subjects for general symptoms were those who reported weekly symptoms of at least one general symptoms; case subjects for mucosal symptoms were those who reported weekly symptoms of at least one mucosal symptoms; case subjects for skin symp- toms were those who reported weekly symptoms of at least one skin symptoms; case subjects for 3 types of SBS symptoms were those who reported weekly symptoms of at least one general symptoms, one mucosal symptoms and one skin symptoms. Control group are subjects who reported never having had the particular type of symptoms. Results were given for general symptoms (at least one), mucosal symptoms (at least one), skin symptoms (at least one) and 3 types of SBS symptoms.

All statistical analyses were conducted with SPSS 17.0. Initially, Chi-square tests were applied to estimate the statistical significance of exposure-associated differences in prevalence. Crude logistic regression models were used to obtain the association between SBS symptoms and house site, gender, history of asthma, allergic rhinitis or eczema, and current smoking. Associations between 18 (question No.5 and Nos.8-24) home exposure indicators and SBS symptoms were evaluated in logistic regression models (enter method) with adjustment for gender, and history of asthma, allergic rhinitis or eczema. Since the number of variables analyzed in the models was relatively large, stepwise multiple logistic regression models (forward elimination, condition method) were used to find the most significant variables for SBS symptoms. Results achieved by the reduced stepwise models were compared with initial logistic regression models.

As a next step, associations between SBS symptoms and the indoor environment risk factors score (as a continuous variable, ranging from 0-14) were calculated by logistic regression models (enter method). The odds ratios (OR) were calculated for one unit increase of the environment risk factor scores on the 14 steps. Then, the category variable on indoor environment risk factors score (score 0 , score 1, score 2 , score 3 and score 4 , as described above) were constructed and applied in logistic regression models for analyzing associations between different score values and SBS symptoms.

Results are presented as OR supplemented with 95\% confidence intervals $(\mathrm{CI})$. Analyses were considered to be statistically significant if the $P$ value was less than 0.05 . In all statistical analysis, two-tailed tests and a $5 \%$ level of significance were applied.

\section{Results}

Totally, 5299 of 7117 questionnaires were returned. The total response rate was $74.5 \%$, with small fluctuations across different kindergartens. Initially, 194 questionnaires for 1, 2, 7 and 8 years old children were excluded due that the numbers in these groups were small. Secondly, questionnaires lacking responses were excluded from the analyses: 155 with no children's gender; 392 questionnaires with no parent's gender; and 308 questionnaires (answered by grandparents) with no history provided for asthma, allergic rhini- 
tis or eczema symptoms. Thus, 4250 complete questionnaires were included in the analysis. Demographic information is shown in Table 1 (percentages for each question are for valid data). Compared with women, men had much fewer allergies and were more often smokers. Table 2 shows the prevalence of home environmental characteristics (percentages for each question are for valid data).

Table 3 shows the prevalence of SBS symptoms answered with "often (every week)" (percentages for each question are for valid data). There was no significant difference on the prevalence of adults' general symptoms, mucosal symptoms, and skin symptoms between groups of subjects with different ages of children's (range 3-6 years old) (data not shown).

For general symptoms, the number of cases was 483; controls numbered 753 . For mucosal symptoms, the number of cases was 300; controls numbered 930. For skin symptoms, the number of cases was 188; controls numbered 1906; for 3 types of SBS symptoms, the number of cases was 32; controls numbered 457.

The OR for house site, gender, history of asthma, allergic rhinitis or eczema symptoms, smoking habit and SBS symptoms calculated in logistic regression models are shown in Table 4. Subjects living in rural areas have fewer general symptoms. A history of asthma, allergic rhinitis or eczema was a significant risk factor for SBS symptoms. A history of asthma, a history of allergic rhinitis, and a history of eczema were all significantly associated with SBS symptoms (data not shown). Current smoking was not associated with SBS symptoms. However, men's current smoking is significantly related to their own general symptoms but not to mucosal and skin symptoms (data not shown).

Associations between home environment, lifestyle and SBS symptoms are shown in Table 5. Living near a main road or highway, redecoration, new furniture, pets and indicators of an impaired indoor environment, such as with dampness, cockroaches, and mosquitoes/flies, were risk factors for each of the three groups of symptoms or for 3 types of SBS symptoms. A laminated floor was associated with risk for general symptoms. Cats and dogs were the most common pets (out of 4250 participants, 219 subjects had cats and 298 subjects had dogs). There was a risk tendency of having cats for mucosal symptoms (aOR(95\% CI): 1.63 $(0.95,2.82), P=0.078)$ and having dogs for general symptoms (aOR(95\% CI): 1.54(0.95,2.50), $P=0.083)$. Cleaning the child's bed room every day and frequently put bedding to sunshine were all protective against SBS symptoms. There was no significant association between different construction times of buildings, area and SBS symptoms in this study (data not shown). Stepwise regression (forward elimination, condition method) was applied to reduce the models, including house site, gender, a history of asthma, allergic rhinitis or eczema, current smoking and all the other home environmental factors in Table 5. Similar results to those in the previous statistical models (enter method used in Tables 4 and 5) were obtained (Table 6).

Logistic regression models for the association between SBS symptoms and the indoor environment risk factor scores (as a continuous variable, range from 0-14) are shown in Table 7 . There were significant associations between each unit increase of risk factor scores and SBS symptoms. Logistic regression models for the associations between SBS symptoms and indoor environment risk factor scores (as a category variable) are shown in Table 8. Generally, categories with higher risk factor scores were associated with a higher risk of having SBS symptoms.

\section{Discussion}

The prevalence of weekly SBS symptoms among parents of young children (3-6 years old) in Chongqing was not high in our study compared with other studies. Indoor environment risk factors were associated with adults' SBS symptoms. The most significant risk factors were living near a main road or highway, dampness indicators, redecoration, new furniture, the presence of cockroaches, rats and mosquitoes/flies. Protective factors in our study were a higher frequency of cleaning and frequently putting bedding to sunshine. Other indicators of an impaired indoor environment increased the risk of having SBS symptoms. Subjects living in rural areas reported less general symptoms than those in urban areas, but did not report fewer mucosal and skin symptoms. The most important risk factors for subjects

Table 1 Demographic information on participating parents $(n=4250)$

\begin{tabular}{|c|c|c|c|c|c|}
\hline & & Total $n(\%)$ & Male $n(\%)$ & Female $n(\%)$ & $P^{\mathrm{a})}$ \\
\hline & & $4250(100)$ & $1257(29.6)$ & 2993(70.4) & \\
\hline $\begin{array}{l}\text { A history of asthma, } \\
\text { allergic rhinitis or eczema }^{\text {b) }}\end{array}$ & Yes & $220(5.5)$ & $43(3.7)$ & $177(6.3)$ & 0.001 \\
\hline Asthma & Yes & $65(1.5)$ & $20(1.6)$ & $45(1.5)$ & 0.840 \\
\hline Allergic rhinitis & Yes & $108(2.5)$ & $18(1.4)$ & $90(3.0)$ & 0.003 \\
\hline Current smoking $^{\mathrm{c}}$ & Yes & $659(16.2)$ & $602(50.9)$ & $57(2.0)$ & $<0.001$ \\
\hline
\end{tabular}

a) $P$ value in $C h i$-square test; b) subjects who have ever had asthma, allergic rhinitis or eczema; c) subject's smoking habit. 
Table 2 Home environmental characteristics of participating parents ( $n=$ 4250)

\begin{tabular}{|c|c|c|}
\hline & & $n(\%)$ \\
\hline \multirow[t]{3}{*}{ House site } & Urban & $2886(71.2)$ \\
\hline & Suburban & $761(18.8)$ \\
\hline & Rural & $403(10.0)$ \\
\hline $\begin{array}{l}\text { Living near a main road or } \\
\text { highway }^{\text {a) }}\end{array}$ & Yes & $1749(44.4)$ \\
\hline \multirow[t]{5}{*}{ Construction time } & Before 1980 & $146(3.7)$ \\
\hline & 1980-1990 & $365(9.1)$ \\
\hline & $1991-2000$ & $897(22.5)$ \\
\hline & 2001-2005 & $1399(35.1)$ \\
\hline & After 2005 & $1184(29.7)$ \\
\hline \multirow[t]{6}{*}{ Area } & $\leqslant 40 \mathrm{~m}^{2}$ & $591(14.6)$ \\
\hline & $41-60 \mathrm{~m}^{2}$ & $531(13.1)$ \\
\hline & $61-75 \mathrm{~m}^{2}$ & 751(18.6) \\
\hline & $76-100 \mathrm{~m}^{2}$ & $1047(25.9)$ \\
\hline & $101-150 \mathrm{~m}^{2}$ & $931(23.0)$ \\
\hline & $>150 \mathrm{~m}^{2}$ & $196(4.8)$ \\
\hline \multirow[t]{6}{*}{ Wall material } & Wall paper & $485(11.7)$ \\
\hline & Paint & $354(8.6)$ \\
\hline & Lime & $763(18.5)$ \\
\hline & Cement & $323(7.8)$ \\
\hline & Emulsion paint & $1908(46.2)$ \\
\hline & Other & 295(7.1) \\
\hline \multirow[t]{5}{*}{ Floor material } & Wood floor & $719(17.6)$ \\
\hline & Cement & $719(17.6)$ \\
\hline & Ceramic tile/stone & $1401(34.3)$ \\
\hline & Laminated & $1162(28.4)$ \\
\hline & Other & $89(2.2)$ \\
\hline Redecoration $^{\text {b) }}$ & Yes & $1199(34.2)$ \\
\hline New furniture ${ }^{c)}$ & Yes & $2209(57.5)$ \\
\hline Dampness ${ }^{\text {d) }}$ & Yes & $1615(44.1)$ \\
\hline Mould spot & Yes & $208(5.4)$ \\
\hline Damp stain & Yes & $329(8.5)$ \\
\hline Water damage & Yes & $339(9.2)$ \\
\hline Condensation & Yes & $1204(30.0)$ \\
\hline Cockroaches ${ }^{\mathrm{e}}$ & Yes & $2961(76.2)$ \\
\hline Rats $^{\text {e) }}$ & Yes & $1647(44.3)$ \\
\hline Mosquitoes/flies e) & Yes & $3361(85.6)$ \\
\hline Current pets & Yes & $856(21.1)$ \\
\hline Mosquito-repellent incense ${ }^{f)}$ & Yes & $3496(86.6)$ \\
\hline Incense $^{f)}$ & Yes & $679(17.1)$ \\
\hline Cleaning every day & Yes & $1642(40.8)$ \\
\hline $\begin{array}{l}\text { Frequently put bedding to } \\
\text { sunshine }\end{array}$ & Yes & $1670(41.0)$ \\
\hline $\begin{array}{l}\text { Frequently open window in } \\
\text { winter }\end{array}$ & Yes & $1436(35.9)$ \\
\hline
\end{tabular}

a) Subject's home located within a distance of 200 meters of a main road or highway; b) subject's home has been redecorated since 1 year before pregnancy; c) subject's home has acquired new furniture since 1 year before pregnancy; d) subject has reported any of the four dampness signs at home: mould spot, damp stain, water damage or condensation on window panels during winter in child's bedroom; e) subject has seen cockroaches/rats/mosquitoes/flies in home before; f) subject has used mosquitorepellent incense/incense in home before.
Table 3 Prevalence of weekly SBS symptoms among participating parents $(\%)$

\begin{tabular}{lccc}
\hline & Total & Female & Male \\
\hline Number of subjects $n(\%)$ & $4250(100)$ & $2993(70.4)$ & $1257(29.6)$ \\
General symptoms $\geqslant 1$ & 11.4 & 11.3 & 11.1 \\
Fatigue & 8.4 & 8.1 & 9.0 \\
Heavy-headed & 1.8 & 1.7 & 2.0 \\
Headache & 1.9 & 1.9 & 1.7 \\
Nausea/dizziness & 1.0 & 1.1 & 0.7 \\
Difficulties concentrating & 2.9 & 2.9 & 2.9 \\
Mucosal symptoms $\geqslant 1$ & 7.1 & 7.3 & 6.6 \\
Itching eyes & 2.1 & 2.2 & 1.8 \\
Runny nose & 2.5 & 2.7 & 2.1 \\
Hoarse & 3.2 & 3.2 & 3.0 \\
Cough & 1.5 & 1.2 & 2.1 \\
Skin symptoms $\geqslant 1$ & 4.4 & 4.5 & 4.3 \\
Dry facial skin & 1.6 & 1.8 & 1.1 \\
Scaling scalp or ears & 3.0 & 2.9 & 3.2 \\
Hands dry & 0.5 & 0.5 & 0.7 \\
3 types of SBS symptoms & & & \\
( $\geqslant 1$ general symptom and $\geqslant 1$ & 0.8 & 0.6 & 1.0 \\
mucosal symptom and $\geqslant 1$ skin & & & \\
symptom) & & & \\
\hline
\end{tabular}

who often have SBS symptoms (with at least one general, one mucosal and one skin symptoms weekly) are a history of asthma, allergic rhinitis or eczema, living near a main road or highway, new furniture, cockroaches, while the most protective factor is "frequently put bedding to sunshine".

Epidemiological studies can be affected by selection bias. In this study, we included all parents from the cross-sectional study, with no prior information on parents' health status. The sample size of this study is reasonably large, and the response rate is good (74.5\%). Thus, an individual selection bias within the study population is fairly unlikely. We do note, however, that the study population is more representative of young parents, especially maternal parents, than of all age range adults in Chongqing.

Recall bias is another potential problem. Subjects may overestimate or underestimate their personal symptoms and/ or signs of indoor environment risk factors. Recall bias for SBS symptoms should not be a big issue in this study, since questions about SBS symptoms are for the last three months. Information bias, in which subjects are aware that certain factors have previously been identified as risks, is another potential problem. However, the SBS risk factors studied in this paper (e.g. wall and floor materials, dampness, odors and lifestyle), are likely not well known among the Chinese population. We also note that the questionnaire has been tested in Sweden, Bulgaria, and USA, and no information bias was found $[30,31,33]$.

In this study, questions on mould spot, damp stain, con- 
Table 4 Associations between house site, gender, a history of asthma, allergic rhinitis or eczema, current smoking, and SBS symptoms OR( $(95 \% \mathrm{CI})^{\text {a) }}$

\begin{tabular}{lcllll}
\hline & & General symptoms & Mucosal symptoms & Skin symptoms & 3 types of SBS symptoms \\
\hline House site & Urban & 1.00 & 1.00 & 1.00 & 1.00 \\
& Suburban & $1.02(0.76,1.38)$ & $0.91(0.65,1.27)$ & $0.74(0.48,1.14)$ & $0.78(0.29,2.12)$ \\
& Rural & $0.58(0.39,0.88)^{*}$ & $1.01(0.64,1.60)$ & $0.80(0.47,1.37)$ & $1.16(0.38,3.50)$ \\
Gender & Female & 1.00 & 1.00 & 1.00 & 1.00 \\
& Male & $0.82(0.64,1.05)$ & $0.86(0.64,1.14)$ & $0.86(0.62,1.19)$ & $1.28(0.62,2.66)$ \\
A history of asthma, & Yes & $6.01(3.33,10.8)^{* * *}$ & $11.2(6.33,19.8)^{* * * *}$ & $5.42(3.28,8.94)^{* * *}$ & $38.1(10.7,136)^{* * *}$ \\
Current sminitis or eczema & Yes & $1.19(0.88,1.62)$ & $1.14(0.80,1.63)$ & $1.08(0.73,1.60)$ & $1.53(0.64,3.69)$ \\
\hline
\end{tabular}

a) $* * * P<0.001, * * P<0.01, * P<0.05$.

Table 5 Associations between home environment, lifestyle and SBS symptoms among participating parents aOR $(95 \% \mathrm{CI})^{\mathrm{a}}$

\begin{tabular}{|c|c|c|c|c|c|}
\hline & & $\begin{array}{c}\text { General } \\
\text { symptoms }\end{array}$ & $\begin{array}{c}\text { Mucosal } \\
\text { symptoms }\end{array}$ & $\begin{array}{c}\text { Skin } \\
\text { symptoms }\end{array}$ & $\begin{array}{c}\text { Three types of } \\
\text { SBS symptoms }\end{array}$ \\
\hline Living near a main road or highway & Yes & $2.16(1.68,2.77)^{* * *}$ & $2.69(2.01,3.61)^{* * *}$ & $1.63(1.18,2.25)^{* *}$ & $3.46(1.51,7.92)^{* *}$ \\
\hline \multirow[t]{2}{*}{ Wall materials } & Others & 1.00 & 1.00 & 1.00 & 1.00 \\
\hline & Emulsion paint/paint & $1.25(0.98,1.60)$ & $1.03(0.77,1.36)$ & $1.12(0.81,1.55)$ & $1.40(0.61,3.19)$ \\
\hline \multirow[t]{3}{*}{ Floor materials } & Cement/ceramic tile/stone & 1.00 & 1.00 & 1.00 & 1.00 \\
\hline & Wood floor & $0.86(0.62,1.19)$ & $0.78(0.53,1.15)$ & $0.70(0.44,1.11)$ & $0.59(0.18,1.99)$ \\
\hline & Laminated floor & $1.37(1.04,1.82)^{*}$ & $1.17(0.84,1.63)$ & $0.96(0.67,1.38)$ & $1.68(0.70,4.03)$ \\
\hline Redecoration & Yes & $2.00(1.52,2.64)^{* * *}$ & $1.66(1.21,2.28)^{* *}$ & $1.66(1.18,2.33)^{*}$ & $2.07(0.87,4.91)$ \\
\hline New furniture & Yes & $2.16(1.68,2.78)^{* * *}$ & $1.67(1.24,2.23)^{* *}$ & $1.38(0.99,1.94)$ & $3.21(1.30,7.90)^{*}$ \\
\hline Mould spot & Yes & $2.53(1.43,4.50)^{* *}$ & $3.98(2.36,6.71)^{* * * *}$ & $1.64(0.84,3.21)$ & $1.39(0.17,11.10)$ \\
\hline Damp stain & Yes & $2.26(1.40,3.65)^{*}$ & $2.35(1.46,3.79)^{* * *}$ & $1.90(1.12,3.22)^{*}$ & $2.66(0.64,11.20)$ \\
\hline Water damage & Yes & $2.27(1.46,3.53)^{* * * *}$ & $3.34(2.04,5.48)^{* * * *}$ & $1.98(1.21,3.25)^{* *}$ & $1.67(0.36,7.73)$ \\
\hline Condensation & Yes & $1.97(1.50,2.58)^{* * * *}$ & $1.98(1.46,2.68)^{* * *}$ & $1.68(1.20,2.34)^{* *}$ & $2.48(1.04,5.89)^{*}$ \\
\hline Cockroaches & Yes & $3.03(2.24,4.11)^{* * *}$ & $2.03(1.43,2.88)^{* * *}$ & $1.48(1.00,2.19)^{*}$ & $3.34(1.11,10.10)^{*}$ \\
\hline Rats & Yes & $1.73(1.34,2.24)^{* * *}$ & $1.93(1.44,2.60)^{* * *}$ & $1.88(1.35,2.61)^{* * * *}$ & $1.22(0.52,2.86)$ \\
\hline Mosquitoes/flies & Yes & $2.72(1.88,3.92)^{* * * *}$ & $2.50(1.58,3.96)^{* * *}$ & $4.28(2.08,8.82)^{* * * *}$ & $8.65(1.07,70.20)^{*}$ \\
\hline Current pets & Yes & $1.61(1.18,2.18)^{* *}$ & $1.46(1.05,2.02)^{*}$ & $1.33(0.91,1.94)$ & $0.96(0.33,2.79)$ \\
\hline Mosquito-repellent incense & Yes & $1.31(0.94,1.82)$ & $1.35(0.91,2.02)$ & $1.41(0.87,2.29)$ & $1.24(0.45,3.43)$ \\
\hline Incense & Yes & $1.59(1.15,2.21)^{* *}$ & $1.43(0.97,2.11)$ & $1.06(0.70,1.61)$ & $1.72(0.59,5.03)$ \\
\hline Cleaning every day & Yes & $0.59(0.46,0.76)^{* * *}$ & $0.50(0.37,0.68)^{* * *}$ & $0.86(0.62,1.18)$ & $0.78(0.35,1.75)$ \\
\hline Frequently put bedding to sunshine & Yes & $0.56(0.44,0.72)^{* * *}$ & $0.50(0.37,0.68)^{* * *}$ & $0.66(0.47,0.92)^{*}$ & $0.28(0.11,0.70)^{* *}$ \\
\hline Frequently open window in winter & Yes & $0.89(0.69,1.15)$ & $0.80(0.59,1.08)$ & $0.92(0.66,1.28)$ & $0.91(0.39,2.16)$ \\
\hline
\end{tabular}

a) Odds ratios were adjusted for gender and the history of asthma, allergic rhinitis or eczema. *** $P<0.001, * * P<0.01, * P<0.05$.

densation and cleaning frequency are based on child's bedroom. This could lead to some miss-classification of parents' exposure. However, we still found strong associations between these and parents' SBS symptoms. Usually, Chinese homes are not very big and bedrooms are close to each other. Thus, dampness and other impaired factors could influence the whole family members.

While statistical models can affect results, consistent results have been obtained from different tests, and good agreement was found between the enter method and step- wise method in logistic regression models.

In our study, general symptoms and mucosal symptoms were reported more frequently than skin symptoms. A study of Chinese junior high school pupils in Taiyuan reported the prevalence of any weekly mucosal symptoms and any weekly general symptoms in Chinese pupils was 3 to 4 times higher than our study [34]. Swedish studies of offices [4] and homes [35] reported a two times greater prevalence of all symptoms than our study.

The present study shows only a small difference between 
Table 6 Significant variables identified in reduced multiple models, obtained by forward stepwise regression (enter model $P$ value level is $P<$ $0.10)$

\begin{tabular}{|c|c|c|}
\hline & $\mathrm{OR}(95 \% \mathrm{CI})$ & $P$ \\
\hline \multicolumn{3}{|l|}{ General symptoms } \\
\hline $\begin{array}{l}\text { A history of asthma, allergic rhinitis } \\
\text { or eczema }\end{array}$ & $3.47(1.54,7.83)$ & 0.003 \\
\hline Living near a main road or highway & $2.06(1.44,2.95)$ & $<0.001$ \\
\hline New furniture & $2.05(1.42,2.94)$ & $<0.001$ \\
\hline Damp stain & $2.43(1.08,5.44)$ & 0.031 \\
\hline Condensation & $1.83(1.25,2.69)$ & 0.002 \\
\hline Cockroaches & $2.57(1.69,3.91)$ & $<0.001$ \\
\hline Mosquitoes/flies & $1.79(1.07,2.99)$ & 0.026 \\
\hline Incense & $1.76(1.08,2.87)$ & 0.023 \\
\hline Cleaning every day & $0.62(0.43,0.90)$ & 0.012 \\
\hline Frequently put bedding to sunshine & $0.60(0.42,0.87)$ & 0.007 \\
\hline \multicolumn{3}{|l|}{ Mucosal symptoms } \\
\hline $\begin{array}{l}\text { A history of asthma, allergic rhinitis } \\
\text { or eczema }\end{array}$ & $6.48(3.21,13.1)$ & $<0.001$ \\
\hline Living near a main road or highway & $2.38(1.60,3.53)$ & $<0.001$ \\
\hline Mould spot & $2.40(1.11,5.18)$ & 0.026 \\
\hline Water damage & $2.74(1.36,5.52)$ & 0.005 \\
\hline Condensation & $1.68(1.12,2.54)$ & 0.013 \\
\hline Cleaning every day & $0.57(0.38,0.87)$ & 0.009 \\
\hline Frequently put bedding to sunshine & $0.59(0.39,0.88)$ & 0.010 \\
\hline \multicolumn{3}{|l|}{ Skin symptoms } \\
\hline $\begin{array}{l}\text { A history of asthma, allergic rhinitis } \\
\text { or eczema }\end{array}$ & $4.49(2.35,8.59)$ & $<0.001$ \\
\hline Living near a main road or highway & $1.68(1.09,2.56)$ & 0.018 \\
\hline Damp stain & $2.63(1.30,5.30)$ & 0.007 \\
\hline Rats & $1.69(1.11,2.59)$ & 0.016 \\
\hline Mosquitoes/flies & $3.17(1.35,7.45)$ & 0.008 \\
\hline Frequently put bedding to sunshine & $0.53(0.34,0.82)$ & 0.005 \\
\hline \multicolumn{3}{|l|}{3 types of SBS symptoms } \\
\hline $\begin{array}{l}\text { A history of asthma, allergic rhinitis } \\
\text { or eczema }\end{array}$ & $19.4(2.59,146)$ & 0.004 \\
\hline Living near a main road or highway & $4.36(1.45,13.1)$ & 0.009 \\
\hline New furniture & $3.14(1.05,9.34)$ & 0.040 \\
\hline Cockroaches & $9.37(1.71,51.4)$ & 0.010 \\
\hline Frequently put bedding to sunshine & $0.24(0.08,0.78)$ & 0.017 \\
\hline
\end{tabular}

Table 7 Associations between SBS symptoms and indoor environment risk factors score (as a continuous variable, range from 0-14)

\begin{tabular}{llc}
\hline & $\mathrm{aOR}(95 \% \mathrm{CI})^{\mathrm{a}}$ & $P$ \\
\hline General symptoms & $1.63(1.47,1.79)$ & $<0.001$ \\
Mucosal symptoms & $1.30(1.20,1.42)$ & $<0.001$ \\
Skin symptoms & $1.24(1.12,1.37)$ & $<0.001$ \\
3 types of SBS symptoms & $1.59(1.25,2.04)$ & $<0.001$
\end{tabular}

a) Odds ratios were adjusted for gender and history of asthma, allergic rhinitis or eczema.
Table 8 Association between SBS symptoms and indoor environment risk factors score (as a category variable)

\begin{tabular}{|c|c|c|}
\hline & $\mathrm{aOR}(95 \% \mathrm{CI})^{\mathrm{a})}$ & $P$ \\
\hline \multicolumn{3}{|l|}{ General symptoms } \\
\hline Score category $0-4$ & - & $<0.001$ \\
\hline Score category 0 & 1.00 & - \\
\hline Score category 1 & $2.20(1.12,4.32)$ & 0.023 \\
\hline Score category 2 & $6.13(3.34,11.3)$ & $<0.001$ \\
\hline Score category 3 & $6.28(3.37,11.7)$ & $<0.001$ \\
\hline Score category 4 & $17.5(9.50,32.1)$ & $<0.001$ \\
\hline \multicolumn{3}{|l|}{ Mucosal symptoms } \\
\hline Score category $0-4$ & - & $<0.001$ \\
\hline Score category 0 & 1.00 & - \\
\hline Score category 1 & $1.39(0.65,2.96)$ & 0.396 \\
\hline Score category 2 & $1.82(0.90,3.68)$ & 0.093 \\
\hline Score category 3 & $1.77(0.88,7.57)$ & 0.109 \\
\hline Score category 4 & $4.05(2.17,7.57)$ & $<0.001$ \\
\hline \multicolumn{3}{|l|}{ Skin symptoms } \\
\hline Score category $0-4$ & - & 0.003 \\
\hline Score category 0 & 1.00 & - \\
\hline Score category 1 & $2.15(0.86,5.34)$ & 0.100 \\
\hline Score category 2 & $2.75(1.17,6.50)$ & 0.021 \\
\hline Score category 3 & $1.62(0.65,4.03)$ & 0.300 \\
\hline Score category 4 & $3.80(1.69,8.56)$ & 0.001 \\
\hline \multicolumn{3}{|c|}{3 types of SBS symptoms } \\
\hline Score category $0-4$ & - & 0.002 \\
\hline Score category 0 & 1.00 & - \\
\hline Score category 1 & $5.11(0.48,54.1)$ & 0.176 \\
\hline Score category 2 & $15.7(1.66,149)$ & 0.016 \\
\hline Score category 3 & $4.71(0.38,59.1)$ & 0.230 \\
\hline Score category 4 & $40.7(4.58,361)$ & 0.001 \\
\hline
\end{tabular}

a) Odds ratios were adjusted for gender and history of asthma, allergic rhinitis or eczema.

genders, consistent with another Chinese study of high school pupils' SBS symptoms [34]. In all other previous studies, women report 2-3 times more SBS symptoms than men $[3,4,18,35-37]$. The reason for this difference between sexes has been discussed $[4,38,39]$. One study used clinical examination on SBS symptoms that indicated the excess symptom prevalence among females is real and not a reporting artifact [38]. It has been suggested that it may be due to females' subjective higher sensitivity [10].

Our finding that a history of asthma, allergic rhinitis or eczema was strongly associated with more reports of SBS symptoms is consistent with reports from other studies $[3,4,34,35,40]$.

A noteworthy finding in our study is that people living near a main road or highway reported more SBS symptoms. A cross-sectional study of SBS symptoms, which was made 
in schools in Taiyuan, China, showed that outdoor air pollution associated with motor vehicle traffic such as $\mathrm{NO}_{2}$ and coal-burning related pollutant $\mathrm{SO}_{2}$ were positively associated with junior high school pupils' SBS symptoms [34]. Exposure to higher self-reported truck traffic on the street of residence was also found to be associated with increased reports of symptoms of asthma, rhinitis, and eczema [41]. Our study did not measure the outdoor pollutants, but one study on the air pollutants in and out of the highway toll gates in Chongqing showed that the indoor and outdoor average concentrations of $\mathrm{CO}, \mathrm{NO}_{2}$ and $\mathrm{PM}_{10}$ had high correlativity and exceed indoor air quality standard [42]. Indoor $\mathrm{PM}_{10}$ level at home was the largest contributor to the population weighted exposure, and city zone and northeast were found to be the highest health risk regions due to particulates in Chongqing [43]. Moreover, a recent study on air fine particles pollution in Chongqing showed that $\mathrm{PM}_{2.5}$ of main traffic route came mainly from vehicle emission [44].

Floor materials were found to be associated with SBS in this study. Compared with cement/ceramic tile/stone floor, laminated floor was a risk factor for SBS symptoms. Laminated floor is a source of chemicals in the house. Redecoration and new furniture were also risk factors for SBS symptoms; the associations were more consistent for new furniture than for redecoration. Redecoration and getting new furniture are often associated with each other due to Chinese traditions. Jaakkola et al. [45] found in a study in Russia that new particleboard, new furniture and new painting were all associated with 8-12 years old children' asthma and allergy; particleboard is part of laminated floor. A Swedish cohort study found indoor painting increased the incidence of general SBS symptoms [26]. A study about SBS in the home environment found renovation, coating materials and volatile organic compounds (VOC) were all positively associated with SBS symptoms [46]. A Japanese study which measured pollutants in newly built buildings reported that higher formaldehyde concentration increased the reporting of SBS symptoms [47]. A Japanese SHS study also showed semi-volatile organic compounds to be related to higher risk of reporting SBS symptoms [27].

Our study also found that using incense in the home was a risk factor for SBS symptoms. In Asian countries where Buddhism and Taoism are the main religions, incense burning can be a daily practice. Incense smoke contains particulate matter, gas products and many organic compounds [48]. A study from Taiwan, China found people who burned incense everyday had on average $43.6 \mu \mathrm{g} / \mathrm{m}^{3}$ higher $\mathrm{PM}_{10}$ exposure than those who only burned incense twice a month [49]. A study on indoor air pollutants and health conducted in United Arab Emirates showed that burning of incense daily was significantly associated with increased headache, difficulty concentrating and forgetfulness [50]. Incense burning is also a common trigger of wheezing among asthmatic children in Oman [51]. Incense smoke in the home may increase the risk of lung cancer among smokers in Chinese men [52]. Reduced incense smoke exposure time could substantially reduce health risks.

The present study reaffirms the findings of many previous studies that "dampness" and biological factors related to dampness are also risk factors. An increased risk for SBS was found when several dampness indicators, appeared simultaneously in a Japanese dwelling study [53]. A Swedish study [29] reported similar findings. Bornehag et al. showed that dampness problems such as condensation on the inside of window panes, floor moisture problems and visible mould and/or damp spots in the dwelling were significantly associated with SBS symptoms [35]. Moisture damage and consequent microbial contamination have been commonly reported from indoor environments. Mold, yeasts, woodrooting fungi, and bacteria could grow in damp buildings [54], and could affect human health by a variety of biological mechanisms, including infections, allergic or hypersensitivity reactions, and irritant reactions. Another Japanese study on female university students' found that nocturnal breathlessness was related to current building dampness [55]. House dust mites, one of the most important allergens associated with allergic asthma, rhinitis and eczema symptoms, are more common in damp environment that has a high relative humidity. A Chinese study on the prevalence of sensitizations in patients with asthma and/or rhinitis showed that house dust mites were the most common allergens in patients with asthma and/or rhinitis in China [56]. A Japanese study reported that an increased concentration of "Microbial Volatile Organic Compounds" (MVOC) of houses including 620 participants was significantly associated with home-related mucosal symptoms [57]. There is an association between bioaerosols and sick building syndrome, and toxicological studies have provided some evidence supporting biological plausibility [58]. However, the extent to which bioaerosol exposure may explain the nonspecific symptoms of the condition is still unclear and needs further research.

The association between pet allergens (such as allergens from cats and dogs), cockroach allergens and human health has been widely discussed in epidemiological studies. Our study did not test allergens from pets and cockroaches, but we found that pet keeping was associated with an elevated risk of general symptoms and mucosal symptoms, consistent with a Norwegian study of four university buildings [59]. The presence of cockroaches was associated with all three types of SBS symptoms in our study. Cockroach allergen is quite common in China [56]. The present study reports for the first time an association between the presence of rats, mosquitoes/flies with SBS symptoms. Cockroaches, rats, mosquitoes/flies were highly significantly associated with damp homes in our study. Allergens from rats and mosquitoes/flies have been reported in recent studies. A study of US households showed increased concentrations of mouse allergen when rodent or cockroach presence was reported and especially when floor mopping was performed instead 
of vacuuming [60]. Mouse allergen levels in schools have been reported substantial, and aerosolization of mouse allergen in classrooms may result in significant exposure for students [61]. Mosquito allergens have been reported to be associated with human health. A study of a Puerto Rican population found that sensitivity to mosquitoes $(\mathrm{OR}=2.25$, $P<0.02)$ increased an individual's likelihood of suffering from rhinitis [62]. Blood-sucking by hematophagous insects can elicit a local allergic reaction, presenting as a wheal or papule, in at least $75 \%$ of the population [63]. In our study, reports of the presence of mosquitoes/flies is common and is associated with the reporting of using mosquito repellent $(P<0.001)$. Whether it was allergens from mosquitoes or chemicals released by burning mosquito-repellent that caused SBS symptoms is still unclear. Further studies are needed to identify causative factors.

Our study also found protective factors. Cleaning every day and frequently putting bedding to sunshine were both negatively related with SBS symptoms. We found no study about the association between cleaning frequency and SBS symptoms in the home environment. Cleaning and putting bedding to sunshine could be associated with reduced exposure to house dust mite allergens. One school study showed that where the desks and curtains were more frequently cleaned, the concentrations of cat and dog allergen in settled dust were lower [64]. The wet mopping cleaning method was associated with more airborne viable bacteria but less settled dust compared with the dry method [64]. Chongqing is a city with high relative humidity all year around, the reporting of damp bedding was quite common in our study (data not shown). It is generally believed that putting bedding to sunshine is good, and to our knowledge, the present study is the first with epidemiological evidence that supports this belief.

\section{Conclusions}

Adults' SBS symptoms are associated with a history of asthma, allergic rhinitis or eczema. Factors in the home environment, especially living near a main road or highway, dampness and new furniture, may increase the risk of SBS symptoms in Chinese residents. The results of this study indicate the need to control material emissions from indoor surface, reduce household dampness and encourage cleaning and putting bedding to sunshine to decrease potential allergens in indoor environment.

This work was supported by the Key National Project of Physical Science (50838009) and National Technology Support Project (2012BAJ02B06). The authors would like to give thanks to the support of the $\mathrm{CCHH}$ workgroup in Chongqing. Thank you to all the parents who filled out questionnaires, and teachers from kindergartens who provided assistance for our survey. And a special thank you to Louise B. Weschler and Zhuohui Zhao for helping with the English language.
1 WHO. Indoor Air Pollutants: Exposure and health effects. WHO EURO Reports and studies. Copenhagen: World Health Organization, 1983. Report No. 1983: 78

2 Akimenko V V, Andersen I, Lebowitz M D, et al. The sick building syndrome. Indoor Air, 1986, 6: 87-97

3 Mendell M J. Non-specific symptoms in office workers: A review and summary of the epidemiological literature. Indoor Air, 1993, 3: 227-236

4 Sundell J. On the Association between building ventilation characteristics, some indoor environmental exposures, some allergic manifestations and subjective symptom reports. Indoor Air, 1994, 4: 7-49

5 Wargocki P, Wyon D P, Sundell J, et al. The effects of outdoor air supply rate in an office on perceived air quality, sick building syndrome (SBS) symptoms and productivity. Indoor Air, 2000, 10: 222236

6 Wargocki P, Lagercrantz L, Witterseh T, et al. Subjective perceptions, symptom intensity and performance: A comparison of two independent studies, both changing similarly the pollution load in an office. Indoor Air, 2002, 12: 74-80

7 Skov P, Valbjorn O, Pedersen B V, et al. Influence of personal characteristics, job-related factors and psychosocial factors on the sick building syndrome. Scand J Work Environ Health, 1989, 15: 266295

8 Zweers T, Preller L, Brunekreef B, et al. Health and indoor climate complaints of 7043 office workers in 61 buildings in the Netherlands. Indoor Air, 1992, 2: 127-136

9 Engvall K, Norrby C, Bandel J. Development of a multiple regression model to identify multi-family residential buildings with a high prevalence of sick building syndrome (SBS). Indoor Air, 2000, 10: 101110

10 Brasche S, Bullinger M, Morfeld M, et al. Why do women suffer from sick building syndrome more often than men? Subjective higher sensitivity versus objective causes. Indoor Air, 2001, 11: 217-222

11 Runeson R, Wahlstedt K, Wieslander G. Personal and psychosocial factors and symptoms compatible with sick building syndrome in the Swedish workforce. Indoor Air, 2006, 16: 445-453

12 Molhave L, Liu Z, Jorgensen A H, et al. Sensory and physiological effects on humans of combined exposures to air temperatures and volatile organic compounds. Indoor Air, 1993, 3: 155-169

13 Bornehag C G, Blomquist G, Gyntelberg F, et al. Dampness in buildings and health. Nordic interdisciplinary review of the scientific evidence on associations between exposure to "dampness" in buildings and health effects (NORDDAMP). Indoor Air, 2001, 11: 72-86

14 Engvall K, Norrby C, Norbäck D. Ocular, airway, and dermal symptoms related to building dampness and odors in dwellings. Arch Environ Health, 2002, 57: 304-310

15 Engvall K, Wickman P, Norbäck D. Sick building syndrome and perceived indoor environment in relation to energy saving by reduced ventilation flow during heating season: A 1 year intervention study in dwellings. Indoor Air, 2005, 15: 120-126

16 Daisey J M, Angell W J, Apte M G. Indoor air quality, ventilation and health symptoms in schools: An analysis of existing information. Indoor Air, 2003, 13: 53-64

17 Redlich C A, Sparer J, Cullen M R. Sick-building syndrome. Lancet, 1997, 349: 1013-1016

18 Björnsson E, Janson C, Norbäck D, et al. Symptoms related to the sick building syndrome in a general population sample: Associations with atopy, bronchial hyper-responsiveness and anxiety. Int J Tuberc Lung Dis, 1998, 2: 1023-1028

19 Wallace L A, Nelson C J, Highsmith R, et al. Association of personal and workplace characteristics with health, comfort and odor: A survey of 3948 office workers in three buildings. Indoor Air, 1993, 3: 193-205

20 Eriksson N, Hoog J, Stenberg B, et al. Psychosocial factors and the 'sick building-syndrome'. A case-referent study. Indoor Air, 1996, 6: $101-110$

21 Sundell J, Lindvall T. Indoor air humidity and the sensation of dryness as risk indicators of SBS. Indoor Air, 1993, 3: 382-390

22 Cain W S. Interactions among odours, environmental factors, and 
ventilation. Indoor Clim, 1979, 257-272

23 Berglund B, Lindvall T. Sensory reactions to sick buildings. Environ Inter, 1986, 12: 147-159

24 Molhave L. Controlled experiments for studies of the sick building syndrome. Ann N Y Acad Sci, 1992, 641: 46-55

25 Lu C Y, Ma Y C, Lin J M, et al. Oxidative stress associated with indoor air pollution and sick building syndrome-related symptoms among office workers in Taiwan. Inhal Toxicol, 2007, 19: 57-65

26 Sahlberg B, Norbäck D, Wieslander G, et al. Onset of mucosal, dermal, and general symptoms in relation to biomarkers and exposures in the dwelling: A cohort study from 1992 to 2002. Indoor Air, 2012, 22: 331-338

27 Kanazawa A, Saito I, Araki A, et al. Association between indoor exposure to semi-volatile organic compounds and building-related symptoms among the occupants of residential dwellings. Indoor Air, 2010, 20: 72-84

28 Engvall K, Hult M. A new multiple regression model to identify multifamily houses with a high prevalence of sick building symptoms "SBS", within the healthy sustainable house study in Stockholm $(3 \mathrm{H})$. Int Arch Occup Environ Health, 2010, 83: 85-94

29 Sahlberg B, Wieslander G. Sick building syndrome in relation to domestic exposure in Sweden-A cohort study from 1991 to 2001. Scand J Public Health, 2010, 38: 232-238

30 Bornehag C G, Sundell J, Hägerhad-Engman L, et al. 'Dampness' at home and its association with airway, nose and skin symptoms among 10851 preschool children in Sweden: A cross-sectional study. Indoor Air, 2005, 15: 48-55

31 Naydenov K, Sundell J, Melikov A, et al. The home environment and allergies among Bulgarian children. In: Proceedings of the 10th international conference on indoor air quality and climate 2005, 2005, Beijing, China. 3574-3575

32 Beko G, Lund T, Nors F, et al. Ventilation rates in the bedrooms of 500 Danish children. Build Environ, 2010, 45: 2289-2295

33 Sun Y, Sundell J. Life style and home environment are associated with racial disparities of asthma and allergy in Northeast Texas children. Sci Total Environ, 2011, 409: 4229-4234

34 Zhang X, Zhao Z, Nordquist T, et al. The prevalence and incidence of sick building syndrome in Chinese pupils in relation to the school environment: A two-year follow-up study. Indoor air, 2011, 21: 462-471

35 Bornehag C G, Sundell J, Hägerhed L, et al. Dampness in dwellings and sick building symptoms among adults: A cross-sectional study on 8918 Swedish homes. In: Proceedings of 7th International Conference on Health Buildings 2003, Singapore. 1: 582

36 Apter A, Bracker A, Hodgson M, et al. Epidemiology of the sick building syndrome. J Allergy Clin Immunol, 1994, 94: 277-288

37 Hodgson M. The sick-building syndrome. Occup Med, 1995, 10: $167-175$

38 Stenberg B, Wall S. Why do women report 'sick building symptoms' more often than men? Soc Sci Med, 1995, 40: 491-502

39 Raw G, Grey A. Sex differences in sick building syndrome. Indoor Air, 1993, 1: 381-386

40 Molina C, Caillud D, Molina N. Sick-building syndrome and atopy. Indoor Air, 1993, 1: 369-373

41 Brunekreef B, Stewart A W, Anderson H R, et al. Self-reported truck traffic on the street of residence and symptoms of asthma and allergic disease: A global relationship in ISAAC phase 3. Environ Health Perspect, 2009, 117: 1791-1798

42 Chen K J, Chen K L, Zhang L J, et al. Characteristics and influencing factors of air pollution in and out of the highway tollgates. Environ Sci, 2007, 28: 1847-1853

43 Wang S, Zhao Y, Chen G, et al. Assessment of population exposure to particulate matter pollution in Chongqing, China. Environ Pollut, 2008, 153: 247-256

44 Fang M J, Zhu G C, Zheng X X, et al. Study on air fine particles pollution prediction of main traffic route using artificial neural network.
In: Proceedings of 2011 International Conference on Computer Distributed Control and Intelligent Environmental Monitoring, 2011, Changsha, Hunan, China. 1346-1349

45 Jaakkola J J, Parise H, Kislitsin V, et al. Asthma, wheezing, and allergies in Russian schoolchildren in relation to new surface materials in the home. Am J Public Health, 2004, 94: 560-562

46 Nakayama K, Morimoto K. Risk factor for lifestyle and way of living for symptoms of sick building syndrome: Epidemiological survey in Japan. Nihon eiseigaku zasshi, 2009, 64: 689-698

47 Takigawa T, Wang B L, Saijo Y, et al. Relationship between indoor chemical concentrations and subjective symptoms associated with sick building syndrome in newly built houses in Japan. Int Arch Occup Environ Health, 2010, 83: 225-235

48 Lin T C, Krishnaswamy G, Chi D S. Incense smoke: Clinical, structural and molecular effects on airway disease. Clin Mol Allergy, 2008, 6: 3

49 Lung S C, Mao I F, Liu L J. Residents' particle exposures in six different communities in Taiwan. Sci Total Environ, 2007, 377: 81-92

50 Yeatts K B, El-Sadig M, Leith D, et al. Indoor air pollutants and health in the united arab emirates. Environ Health Perspect, 2012, 120: 687-694

51 Al-Rawas O A, Al-Maniri A A, Al-Riyami B M. Home exposure to Arabian incense (bakhour) and asthma symptoms in children: A community survey in two regions in Oman. BMC Pulm Med, 2009, 9: 23

52 Tse L A, Yu I T, Qiu H, et al. A case-referent study of lung cancer and incense smoke, smoking, and residential radon in Chinese men. Environ Health Perspect, 2011, 119: 11

53 Kishi R, Saijo Y, Kanazawa A, et al. Regional differences in residential environments and the association of dwellings and residential factors with the sick house syndrome: A nationwide cross-sectional questionnaire study in Japan. Indoor Air, 2009, 19: 243-254

54 Nevalainen A, Pasanen A L, Niininen M, et al. The indoor air quality in Finnish homes with mold problems. Environ Int, 1991, 17: 299302

55 Takaoka M, Norbäck D. The home environment of Japanese female university students - association with respiratory health and allergy. Indoor Built Environ, 2011, 20: 369-376

56 Li J, Sun B, Huang Y, et al. A multicentre study assessing the prevalence of sensitizations in patients with asthma and/or rhinitis in China. Allergy, 2009, 64: 1083-1092

57 Araki A, Kawai T, Eitaki Y, et al. Relationship between selected indoor volatile organic compounds, so-called microbial VOC, and the prevalence of mucous membrane symptoms in single family homes. Sci Total Environ, 2010, 408: 2208-2215

58 Laumbach R J, Kipen H M. Bioaerosols and sick building syndrome: Particles, inflammation, and allergy. Curr Opin Allergy Clin Immunol, 2005, 5: 135-139

59 Bakke J V, Norbäck D, Wieslander G, et al. Pet keeping and dampness in the dwelling: Associations with airway infections, symptoms, and physiological signs from the ocular and nasal mucosa. Indoor Air, 2007, 17: 60-69

60 Cohn R D, Arbes S J Jr, Yin M, et al. National prevalence and exposure risk for mouse allergen in US households. J Allergy Clin Immunol, 2004, 113: 1167-1171

61 Permaul P, Hoffman E, Fu C, et al. Allergens in urban schools and homes of children with asthma. Pediatr Allergy Immunol, 2012, 23: 543-549

62 Nazario S, Zaragoza R, Velázquez V, et al. Allergen sensitivity (mites, insects, and pets) in a Puerto Rican population. P R Health Sci J, 2012, 31: 24-28

63 Przybilla B, Ruëff F. Insect stings: Clinical features and management. Dtsch Arztebl Int, 2012, 109: 238-248

64 Smedje G, Norbäck D. Irritants and allergens at school in relation to furnishing and cleaning. Indoor Air, 2001, 11: 127-133

Open Access This article is distributed under the terms of the Creative Commons Attribution License which permits any use, distribution, and reproduction in any medium, provided the original author(s) and source are credited. 